\title{
Masters in Information Systems: A Web-Centric Model Curriculum
}

\author{
John Gorgone \\ Bentley College, Waltham, MA, USA \\ igorgone@lnmta.bentley.edu
}

\author{
Vijay Kanabar \\ Boston University, Boston, MA, USA \\ kanabar@bu.edu
}

\begin{abstract}
Web Technology has changed conventional Information Systems (IS) and conventional Information Technology (IT) as we know it. There is no doubt that Web technology will provide the foundation for most future software systems. IS curriculum therefore needs to be brought up to date to reflect this reality. In this paper we update our earlier research leading to the design of a graduate model curriculum for Information Systems and describe a generic web-centric Information Systems Masters curriculum model. It is strong on web-technology and its goal is to produce students who are comfortable with both today's technology and technology of the future. Universities and colleges can adapt this curriculum model to design a new Masters in IS curriculum or simply to bring up to date any existing IS/IT curriculum. The model suggests new core concentration courses, and concentration electives.
\end{abstract}

Keywords: web technology, masters curriculum, Information Systems, IS, IT

\section{Introduction}

The IS discipline is an essential part of business and government organizations. Information Systems are complex systems requiring both technical and organizational expertise for design, development, and management. They affect not only operations but also competitive strategy. ${ }^{1}$ Due to this importance many colleges and universities offer a Bachelors and a Masters degree in Information Systems today. However, Web Technology has recently come into the picture and changed conventional computing, as we know it. Reflecting this change, the IS discipline has evolved as well. Our paper revises an initial model curriculum design effort based on extensive research of all available Information Systems curriculum in the United States that clearly offered a Masters in Information Systems. ${ }^{2}$ We decided not to consider programs that offered only a minor in Information Systems. MBA programs consequently were not considered. We had evaluated each program for the following general attributes such as: Where it is housed, degree label offered, number of semester hours, professional/doctoral, undergraduate pre-requisite degree required and GMAT, GRE or GPA expectations if any. Finally for each program we tabulated the following course attributes: Prerequisite courses in the program and core courses in the program. In this paper we underscore some of the valuable results from our earlier work and incorporate additional research results in this paper.

Material published as part of these proceedings, either on-line or in print, is copyrighted by Informing Science. Permission to make digital or paper copy of part or all of these works for personal or classroom use is granted without fee provided that the copies are not made or distributed for profit or commercial advantage AND that copies 1) bear this notice in full and 2) give the full citation on the first page. It is permissible to abstract these works so long as credit is given. To copy in all other cases or to republish or to post on a server or to redistribute to lists requires specific permission from the publisher at Publisher@intormingscience.org

\section{Scope}

In addition to programs that offer an MS in IS, other programs that offer an e-Commerce or eBusiness Masters have also been considered in this research effort. Only degree programs in the United States were considered at present. Scope may be increased to include Canada, Europe, Asia and Australia in the near future. 


\section{Why Propose a Web-Centric Model?}

As indicated earlier the IS discipline is a rapidly changing field. To bring the IS curriculum up to date today it should integrate new domains of knowledge such as e-commerce and e-business as well as design of interoperable Internet-based systems, implementation of Internet-based systems, web content management, web-enabled business management, and new techniques and strategies such as CRM (especially eCRM). Of course students should have marketable skill sets. A good web-centric curriculum could produce students that are knowledgeable in topics such as "Strategic XML" and "Building Web Services". With knowledge of web services for example, they will also be able to introduce and leverage distributed (object) computing and integrate applications both within an organization and between business partners.

Without a web-centric curriculum students might possibly not have the opportunity to fully understand a web services oriented framework or recommend a web services solution. However as you will shortly see a web-centric model would allow students to focus on advanced web solutions involving SOAP, WSDL and UDDI.

\section{Relationship with the IS Body of Knowledge}

The web-centric model compares well with the IS Body of knowledge. According to the IS'97 Model Curriculum, the IS body of knowledge consists of three major subject areas:

- Information Technology

- Organizational and management Concepts

- Theory and Development of Systems

The Information Technology component refers to knowledge elements such as: computer architectures, algorithms, programming languages, operating systems (OS), telecommunications, database and artificial intelligence (AI). While some of the knowledge elements such as algorithms, AI and computer architectures receive less attention in a web-centric model; other areas such as languages, telecommunications, database and even OS are covered fully.

Organizational and management Concepts pertain to knowledge elements such as: organizational theory, organizational behavior, IS Management, Legal and Ethical Aspects of IS, Interpersonal Skills, Decision Theory and Professionalism. A strongly recommended elective such as - eCRM and ePrivacy in our model would cover knowledge elements such as Legal and Ethical aspects and Professionalism. The other knowledge elements are easily obtainable from electives (see sample choices available for Boston University's MS program.)

Theory and Development of Systems pertains to knowledge elements such as: systems analysis, development concepts and methodologies, project management, risk management, and systems implementation. All of the knowledge elements figure prominently in our model.

\section{Exit Objectives for Graduates}

Our current model sets the same standards and exit objectives for graduates obtaining a Masters in Information Systems as before. For instance, MS IS students must have hands-on experience in various aspects of software design, and implementation and comprehensive knowledge about the state-of-the-art in information technology. Note that many reports and surveys from the industry reveal that the business world today wants graduates with good technical skills ${ }^{3}$. The web-centric MS IS model would ensure this objective. MS IS programs should be able to produce graduates that meet the following IS needs of the business world: 
- Broad business perspective, and business experience/skills

- Systems/IS skills, including hardware and software programming skills

- Communication/interpersonal/ team skills

- Analytical and thinking skills

- Real world experience/internship

- Cutting-edge technology knowledge

Additionally, it is our expectation that students with an MS degree should be able to assist an organization deal with major Information Systems challenges such as: ${ }^{4}$

- Assess the different information needs of different organizational levels within an organization.

- Design or fully participate in designing systems for an organization that are both competitive and efficient.

- Create an Information Systems architecture that aligns with the organization's goals.

- Determine the business value of systems.

- Design systems that people can control, understand, and use in a socially and ethically responsible manner.

\section{Users of the MS IS Model}

The following entities will find a graduate model curriculum in Information Systems useful.

- Academic Heads of Information Systems interested in benchmarking their MS program with other colleges and universities.

- Academic Heads interested in introducing a new Information Systems program.

- Information Systems faculty interested in introducing new courses.

\section{Research Methodology and Results}

In order to create a base model of MS IS programs we evaluated each program for the following general attributes:

- Where it is housed

- Degree Label offered

- Number of semester hours

- Professional/Doctoral

- Undergraduate pre-requisite degree required

- GMAT, GRE or GPA expectations if any.

Finally for each program we tabulated the following course attributes:

- 41 courses often taught in the program

\section{Results: Different Degree Labels}

We expected and were not surprised with the many different labels for Information Systems. However, we examined each such program individually and rejected programs that were radically different from a 
Masters in Information Systems

typical Information Systems curriculum. A sampling of different labels is presented in Table 1: Sample Degree Labels Offered.

Table 1: Sample Degree Labels Offered

\begin{tabular}{|l|}
\hline MS MIS \\
\hline MS CIS \\
\hline MIS \\
\hline MS IS \\
\hline MS ITS \\
\hline MS MSA \\
\hline MA MIS \\
\hline MS ISM \\
\hline MS MCS \\
\hline MS DIS \\
\hline MS SM \\
\hline MMIS \\
\hline MOIS \\
\hline
\end{tabular}

\section{Generic IS Curriculum Model}

We developed the generic IS curriculum model (non web-centric) from our research, as shown in Figure 1 .

\section{Prerequisite}

Usually no credits are awarded for prerequisite courses.

IS P0 Knowledge Work Software Took Kit (suitable for graduate level students) and IS P0 Programming Course.

\section{Core Courses}

IS95.01 Fundamentals of Information Systems

IS95.04 Information Technology Hardware and Software

IS95.05 Programming, Data, File and Object Structures

IS95.06 Telecommunications

IS95.07 Analysis and Logical Design

IS95.08 Physical Design and Implementation with DBMS

IS95.09 Physical Design and Implementation with Programming Environments

IS95.10 Project Management and Practice

\section{Additional Courses Often Taught}

IS 02 Personal Productivity with Information Technology 


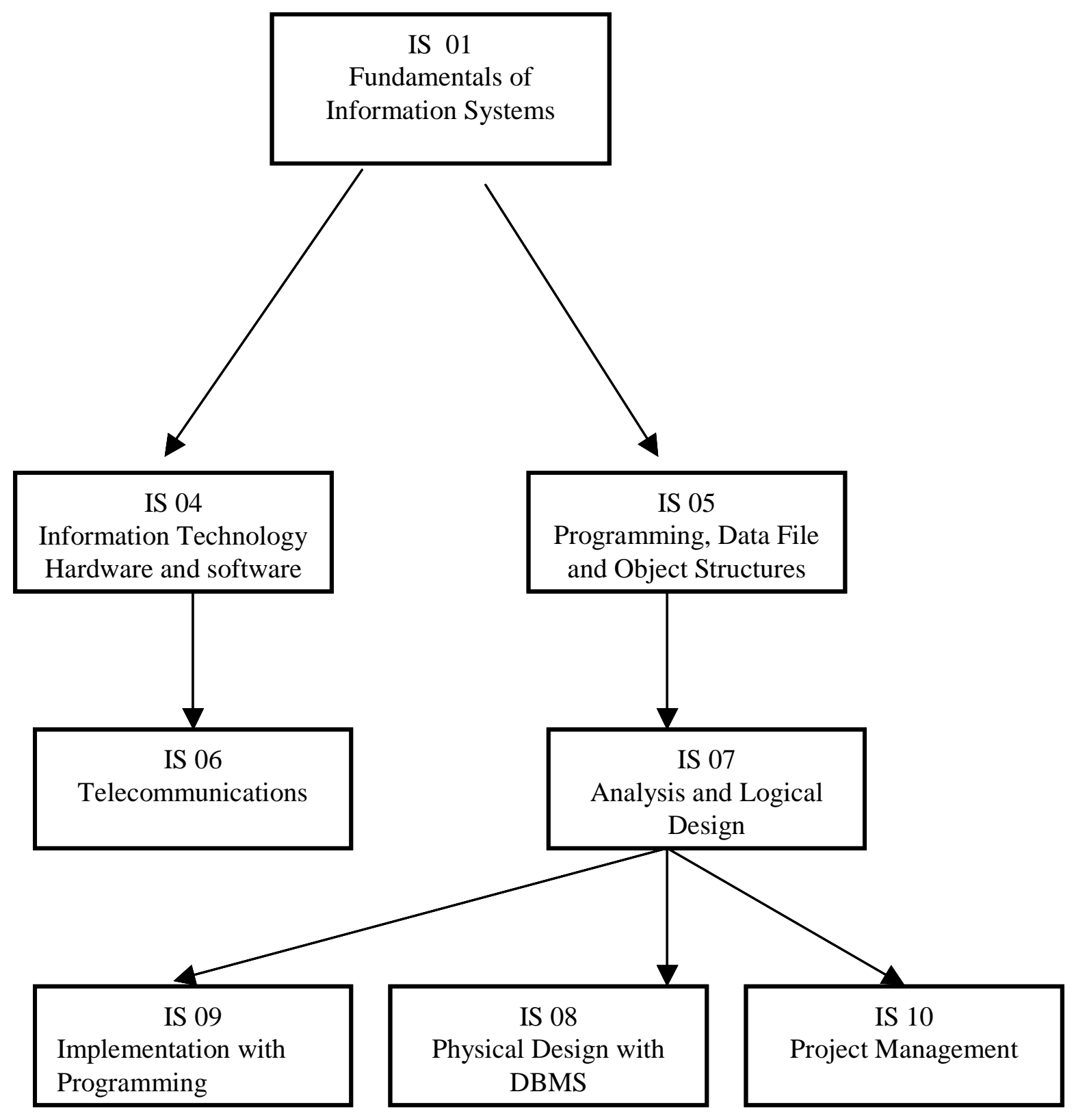

Figure 1: General IS Curriculum Model

IS 03 Information Systems Theory and Practice

O-11 Information Technology and Organizational Strategy

O-1 Organization Management and Evaluation of Information Resources

O-13 Technology and Development of Client-Server Systems

O-16 Collaborative Work, Decision Support, and Executive Support Systems.

O-17 Human Computer Interaction and Interface Design

O-24 Thesis or O-26 Internship 


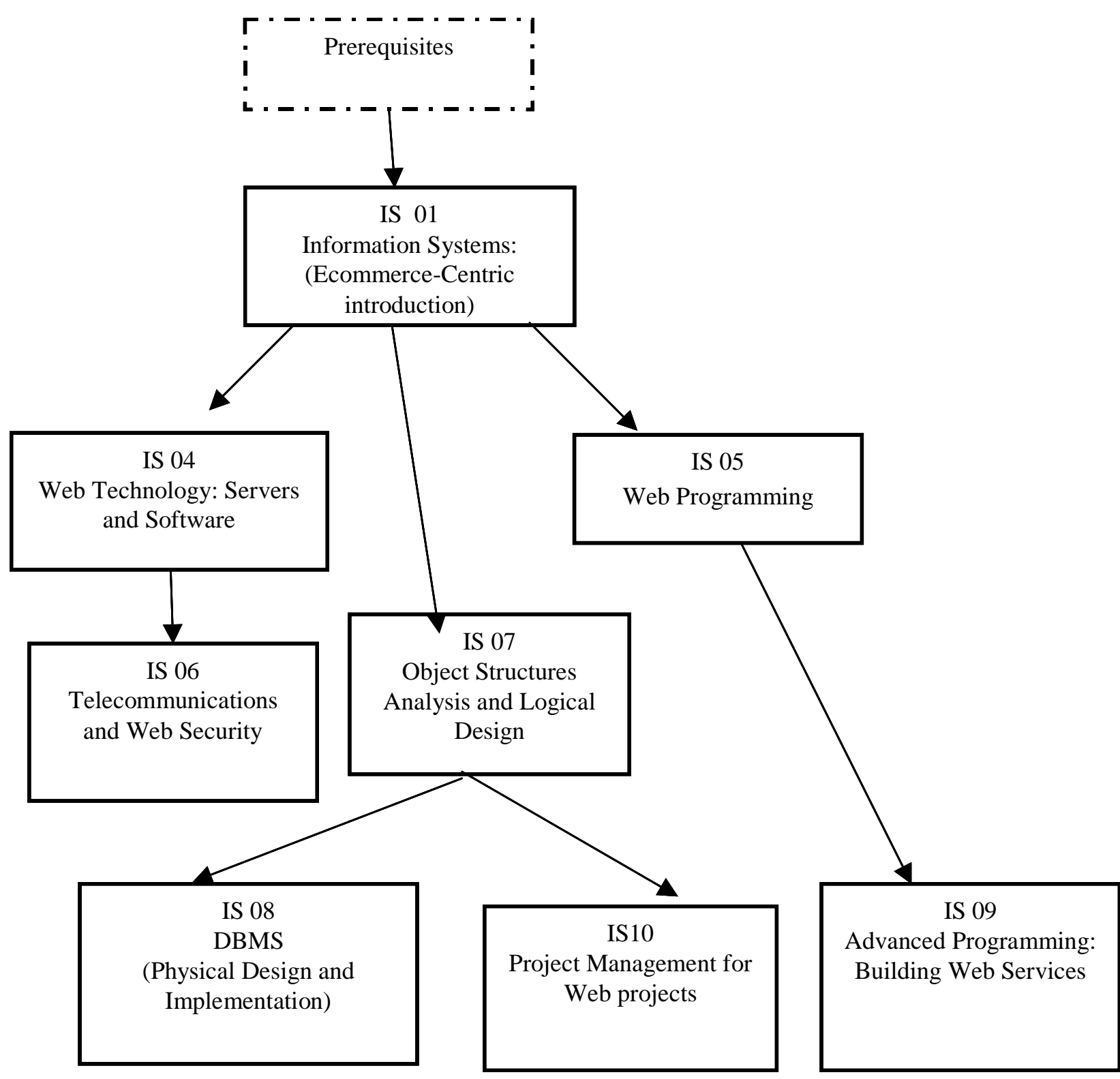

Figure 2: Web-Centric Curriculum Model

\section{Web Centric Curriculum Model}

In addition to the labels identified in Table 1 for MS IS degrees we identified some new labels. We have not listed labels such as E-Commerce Management as they appeared to be more MBA oriented and not MS IS oriented. They are shown below in Table 2.

Table 2: New Sample Degree Labels Offered

MS ELECTRONIC COMMERCE OR MS E-COMMERCE

MS E-BUSINESS 


\begin{tabular}{|l|}
\hline MS WEB TECHNOLOGY \\
\hline MS INTERNET TECHNOLOGY \\
\hline MS WEB DESIGN \& DEVELOPMENT \\
\hline
\end{tabular}

\section{Web-Centric Curriculum Model}

We have used the similar course labels and numbers where possible (see Figure 2.)

\section{Prerequisite}

Usually no credits are awarded for prerequisite courses. Typically students must demonstrate proficiency in the following areas: financial analysis, financial and managerial accounting, and computer technology and applications (including database, spreadsheet, and word processing applications).

\section{Concentration Prerequisites}

Some MS programs that are ecommerce oriented request additional prerequisites such as: Financial and Managerial Accounting, Financial Analysis, and Business Communications (recommended for International Students)

\section{Core Courses}

IS .01 Information Systems: An E-Commerce centric introduction

IS .04 Web Technology: Servers and Software

IS .05 Web Programming

IS .06 Telecommunications and Web Security

IS .07 Object Structures: Analysis and Logical Design

IS .08 DBMS: Physical Design and Implementation

IS .09 Advanced Programming: Building Web Services

IS .10 Project Management for Web Projects (and Practice)

\section{Additional Web-Centric Courses Often Taught}

O 11 Ecommerce Marketing

O 12 Ecommerce and Ebusiness Strategies

O 13 Information Systems Theory and Practice

O 13 ECustomer Relationship Management

O 14 EPrivacy

O 15 B2B

O 16 Internet-based Supply Chain Management

O 17 GUI Design and Implementation for Web Based Systems 


\section{Comments}

(1) The sequence of the courses is evident from the diagram. Typically IS 1, IS 4, IS 5 and IS 7 are taken before the corresponding advanced courses are taken.

(2) With regards to IS 01 Information Systems we are suggesting an E-Commerce centric introduction to Information Systems. This would alleviate the need to have two introductory courses. For example a text book such as: MANAGEMENT INFORMATION SYSTEMS FOR THE INFORMATION AGE, Third Edition, by Haag et al provides several chapters and case studies dealing with Ecommerce and Ebusiness. ${ }^{5}$ We believe several similar IS books will now come into the market place and provide chapters that have been reorganized to incorporate increased coverage of E-Commerce and E-Business.

(3) A very valuable course in the web-centric IS curriculum would be $O 12$ Ecommerce and Ebusiness Strategies. A textbook such as e-Business 2.0, by Kalakota \& Robinson, would introduce students to concepts pertaining to CRM, ERP, \& SCM and also provide students with the latest strategies and techniques pertaining to e-business. ${ }^{6}$

\section{Where We Are Going From Here}

Developing an on-line Web repository. Such a repository would provide hyperlink to various web-centric programs and provide the opportunity to other colleges to enter a hyperlink of their program. In this context we are also planning to develop an on-line Web Survey and request additional information about the Web-Centric model. While we do have basic course description and topics for each of the courses in the model, our goal would be to create a web site that provides comprehensive textbook information for all useful core and electives described in this paper.

\section{Conclusion}

In this paper we have upgraded our original MS IS model for web-centric MS IS curricula. Such a model will be useful to Academic Heads of Information Systems and other faculty members interested in comparing their Web Technology programs with a generic model. It will also assist them with identifying new courses.

\section{Biographies}

Dr. John T. Gorgone is a Professor of Computer Information Systems and recipient of the Richard H. Rubin Professorship. In 1999, he received the Educator of the Year Award "for Outstanding and Exceptional Service to the Field of Information Systems Education" from the Association for Information Technology Professionals. He has chaired national computer conferences and has played a major role in developing ACM/AIS/AITP national curricula models in information systems. Professor Gorgone has over 170 published and/or presented professional papers and has been frequently noted in biographical listings -- most recently in 2000 Outstanding Scientists of the 20th Century (2000). He published articles in MIS Quarterly, Information Strategy: The Executive's Journal, The Data Base for Advances in Information Systems, Information and Management, Computing Research News, and Washington Report. His research interests include wireless communications, computer networks, IT work force issues, computer science and information systems curricula and accreditation standards. He is currently examining the feasibility of accrediting computer information science/systems/technology programs in a study funded by the National Science Foundation. Dr. Gorgone has extensive experience as a management and information technology consultant to Fortune 500 companies, U.S. State boards of higher education and college presidents. 
Vijay Kanabar is an Associate Professor of Computer Science at Boston University. He has a $\mathrm{PhD}$ in Information Systems (Manitoba). His research interests are IS curriculum development, project management, ecommerce and web technology, database systems and multi-tiered architectures.

${ }^{1}$ Davis, D.B., Gorgone, J., Couger, JD, Feinstein, D., \& Longenecker, H. (1997). Model Curriculum and Guidelines for Undergraduate Degree Programs in Information Systems. The DATA BASE for Advances in Information Systems, 29, 1-94.

${ }^{2}$ Gorgone, J., \&. Kanabar, V. (1997). Status of Master's Degree Programs in Information Systems. Procedings of the 12th Annual Conference of International Academy for Information Management (December), International Academy for Information Management.

${ }^{3}$ Maglitta, J. (1995, December). Computer Careers: Special Report, Computer World, 121-124

${ }^{4}$ Laudon, C., \& Laudon, J. (1994). Management Information Systems (3rd ed.). New York: Macmillan.

${ }^{5}$ Haag, S., Cummings, M., \& Dawkins, J. (2002). Management Information Systems for the Information Age (3rd ed.). Boston: Irwin McGraw-Hill.

${ }^{6}$ Kalakota, R., \& Robinson, M. (2001). E-Business 2.0. Boston: Addison-Wesley.

\section{Appendix: Course Descriptions}

\section{IS 01 Information Systems (An eCommerce centric introduction)}

This course should examine the changing role of information technology and management information systems in organizations. Role of IT and MIS as competitive tools. Examine the current and potential impact of information and information technology on all aspects of his or her position, firm, and industry systematically. Since this is a graduate level course, IS 01 will focus on IT from the perspective of managers. For example, case studies describing the role of IT and MIS as competitive tools should be covered extensively. Since e-business is the next major revolution-students will be expected to understand the technology of ecommerce and the impact of ecommerce on MIS.

Sample Topics: IT systems, strategic and competitive opportunities, databases and data warehouses, decision support systems, networks, emerging technologies, planning for IT systems, developing IT systems, managing IT systems. With regards to Ecommerce and Ebusiness: Business to Consumer ECommerce, Business to Business E-Commerce, The role of Government in Promoting E-Commerce, ECommerce Payment Systems and Digital Cash, Security and Privacy Issues; Ebusiness vs. Ecommerce.

\section{IS 04 Web Technology: Servers and Software}

Introduce client/server architecture and multi-tiered architecture as it pertains to web technology. Provides fundamentals of hardware and system software as well as middleware. The course also provides some introduction to the following topics: Telecommunication, Web Server Administration, Web server planning, HTTP, and Security.

Sample Topics: Web Server Administration: understanding of what is required to configure a web server and keep it running. Planning of a web server - from sizing and performance issues to choosing server software and an ISP. How the HTTP protocol works, how ASP/JSP/CGI programs execute various methods for publishing documents on a web server. Detect and fix problems and how to generate server statistics by analyzing server log files. Web Security introduction--covers the security issues surrounding the Web. Types of threats and protecting the machines and users against these threats, web client security. 


\section{IS 05 Web Programming}

This course presents a complete immersion into Web Programming. HTML language is covered in this course if students have not picked it up else where. Other topics include Dynamic HTML: Scripting using JavaScript, VBScript and XML; Server side components such as CGI, ASP, and PERL are also introduced in this course. The course focuses on building competencies in the client/server development for Web sites used in the Internet/Intranet environments. Java is also introduced here.

Sample Topics: At the outset a decision has to be made whether Java will be used as a Web Programming language or not. Topics covered regardless of decision: HTML, XML, DHTML, and CSS. If the school decides to use Java as the primary Web programming language then less focus is placed on JavaScript, CGI/PERL and VBScript and ASP is omitted. Otherwise less focus is on Java and extensive focus on VBScript and ASP.

\section{IS 06 Telecommunications and Web Security}

This course provides networking knowledge needed to succeed in the Web environment. Topics can range from networking topology to networking media, network standards to Ethernet, optimization to streaming media, web protocols to DSL access. Advanced web security concepts need to be covered in this course as well such as intrusion detection and recovery, viruses, firewalls, encryption, PGP. From the ebusiness perspective topics covered include Electronic Payment mechanisms (and security of transactions), clientside security, web document security, server side security, securing electronic commerce environments, analysis of the major classes of Electronic Commerce security, and survey of new trends.

Sample Topics: Fundamentals: network characteristics, network models, WANs, internetworks, intranets, and extranets; Architecture: packet-switched networks, client/server architectures, Ethernet, network components, and more; Protocols: IP, TCP, UDP, DNS, HTTP, SMTP, MIME, FTP, MAC addresses, and more; Applications: mail, web services, FTP, push and pull technologies, and streaming multimedia; Connectivity: DSL, T-1/T-3, ISDN, wireless networks, and cable modem connectivity; Security: Encryption, SSL, SHTTP, HTTP, SET, firewalls, sniffers, proxy servers, and VPNs; Web Server Support: Web development, scripting, JavaScript, CGI, server-side APIs, and dynamic content; intrusion detection and recovery: Detecting an Attack and Recovering from an Attack ; Secure online transactions: Encryption; Secure Socket Layer; Certificate Authorities; Access Control Lists. Client side security topics: Active content attacks, Browser bugs, Webmaster's attacks, Cookies, SSL weakness

\section{IS 07 Object Structures: Analysis and Logical Design}

This course focuses on the systems development life cycle for creating web applications. The focus is on object-oriented systems analysis and design. It introduces different paradigms for developing web software, the key stages of the life cycle and identifies key deliverables for each stage. Object technology is introduced in this course and importance of object-oriented paradigm is underscored. The students should be able to identify best architectural methods for any project, understand concepts such as abstraction, refactoring and architectural prototyping.

Sample Topics: Information Systems Development, Object Oriented Analysis. Object-Oriented Design Players in the Systems Game, UML, Use cases, class models, Project Management, Systems Analysis, Requirements Discovery, Data and Process Modeling, Feasibility Analysis, Systems Design Application Architecture, Output Design and Prototyping, Input Design and Prototyping, User Interface Design 


\section{IS 08 DBMS: Physical Design and Implementation}

The focus of such a course is two fold--first to introduce database concepts and to focus on data and information modeling (including systems design) and implementation within a DBMS environment. Students also learn to use a popular DBMS system such as Oracle.

Sample Topics: Database Environment, DBMS, data models, relational model, object model (OODBMS), principles of database (relational algebra), SQL, normalization. Relational data base design, implementation and support. Each student/team can be asked to design and implement a small relational data base system using Oracle. Students should be able to connect web applications to a DBMS and store and update data remotely via a web interface.

\section{IS 09 Advanced Programming: Building Web Services}

This course provides students knowledge about the software systems for the next decade. It's objective is to map student knowledge from today's systems to the Internet enabled systems of the future. This course also provides students an opportunity to do some advanced web programming. Web services is the next frontier in distributed computing - enabling any organization to make its data and information available any where in the world. Students also learn XML in this course and understand how to use XML technology strategically.

Sample Topics: eXtensivble Markup Language (XML), Document Type Definition (DTD), Schema, Extensible Style-sheet Language (XSL), XSL-Transformation, Document Object Model (DOM), Simple API for XML (SAX), Service Oriented Architecture Protocol (SOAP), Web Services Description Language (WSDL), Mapping between native data structures and XML, Universal Description, Discovery and Integration (UDDI), J2EE Web Services. The Microsoft vs. Java dilemma persists in this course. If the department chose Java as a web programming language of choice they would focus on building web services with Java. The other choice is Microsoft .NET Web Services.

\section{IS 10 Project Management for Web Projects (and Practice)}

Focus is on developing and implementing a business plans that works in the online community. Basic project management concepts such as project planning, organizing and control are also introduced in this project. The students learn various functional areas such: Project scope management, risk management, time management, quality management, cost management, human resource management and communications.

Sample Topics: The topics listed above are introduced. (The Project Management Institute curriculum could be adopted.) This Project management course could be blended with a Web Marketing flavor. Students could be assigned to envision a marketing strategy and find the technology to support it, reach the clients that are right for the business, develop your plans into reality, manage the project, the team, and the client; Get to the product launch-and through it understand the special legal issues surrounding Internet communications. 